\title{
A Comparative Performance Evaluation of Some Novel "Green" and Traditional Antiscalants in Calcium Sulfate Scaling
}

\author{
Konstantin Popov, Galina Rudakova, Vladimir Larchenko, Mariya Tusheva, \\ Semen Kamagurov, Julia Dikareva, and Natalya Kovaleva
}

PJSC “Fine Chemicals R\&D Centre”, Krasnobogatyrskaya 42, Str. 1, Moscow 107258, Russia

Correspondence should be addressed to Konstantin Popov; ki-popov49@yandex.ru

Received 25 June 2016; Accepted 14 September 2016

Academic Editor: Gianluca Cicala

Copyright (c) 2016 Konstantin Popov et al. This is an open access article distributed under the Creative Commons Attribution License, which permits unrestricted use, distribution, and reproduction in any medium, provided the original work is properly cited.

A relative ability of industrial samples of four phosphorus-free polymers (polyaspartate (PASP); polyepoxysuccinate (PESA); polyacrylic acid sodium salt (PAAS); copolymer of maleic and acrylic acid (MA-AA)) and of three phosphonates (aminotris(methylenephosphonic acid), ATMP; 1-hydroxyethane-1,1-bis(phosphonic acid), HEDP; phosphonobutane-1,2,4tricarboxylic acid, PBTC) to inhibit calcium sulfate precipitation is studied following the NACE Standard along with dynamic light scattering (DLS), scanning electron microscopy (SEM), and X-ray diffraction (XRD) technique. For the $0.5 \mathrm{mg} \cdot \mathrm{dm}^{-3}$ dosage, the following efficiency ranking was found: MA-AA ATMP > PESA (400-1500 Da) > PASP (1000-5000 Da) $\gg$ PAAS (3000-5000 Da) PBTC HEDP. The isolated crystals are identified as gypsum. SEM images for PESA, PASP, PAAS, and HEDP and for a blank sample indicated the needle-like crystal morphology. Surprisingly, the least effective reagent PBTC revealed quite a different behavior, changing the morphology of gypsum crystals to an irregular shape. The DLS experiments exhibited a formation of 300 to $700 \mathrm{~nm}$ diameter particles with negative $\zeta$-potential around $-2 \mathrm{mV}$ for all reagents. Although such $\zeta$-potential values are not capable of providing colloidal stability, all three phosphonates demonstrate significant gypsum particles stabilization relative to a blank experiment.

\section{Introduction}

Calcium sulfates are common scale-deposit minerals in water treatment plants and oil and gas industry, causing significant plugging of pipe lines and membranes and increasing the production cost [1]. Commercial scale inhibitors (antiscalants) are widely used for preventing scale deposits in pipes, heat exchangers, and desalination facilities [1-4].

Commonly used commercial antiscalants are represented by three chemical families: polyphosphates (hexametaphosphate (HMP), tripolyphosphate (TPP), etc.), organophosphonates (aminotris(methylenephosphonic acid), ATMP; 1-hydroxyethane-1,1-bis(phosphonic acid), HEDP; 2-phosphonobutane 1,2,4-tricarboxylic acid (PBTC), etc.), and organic polyelectrolytes (polyacrylates (PA); polycarboxysulfonates). Among these, the organophosphonates are dominating recently at the World market [5]. At the same time, phosphorus-based inhibitors are hardly biodegradable and persist for many years after their disposal, which leads to eutrophication problems $[4,6]$. Phosphorus discharges are therefore regulated in many countries worldwide, and permissible limits are constantly decreasing [4].

Increasing environmental concerns and discharge limitations have forced the scale-inhibitor chemistry to move toward "green antiscalants" that are readily biodegradable and have minimal environmental impact. Intensive efforts are applied recently to develop the "green" alternatives to organophosphonates and nonbiodegradable polyacrylates [2, 4, 7-9]. Among these novel inhibitors, such chemicals as polymaleates (PMA), polyaspartates (PASP), and polyepoxysuccinates (PESA), as well as their various derivatives including copolymers with $\mathrm{PA}$, are the most promising.

It is important to note that the new antiscalants should have acceptable levels of performance at cost-effective dose rates. This requirement raises a problem of reliable tests, which permit a correct "old red" and "novel green" inhibitors 
TABLE 1: Polymers studied as scale inhibitors in calcium carbonate supersaturated solutions.

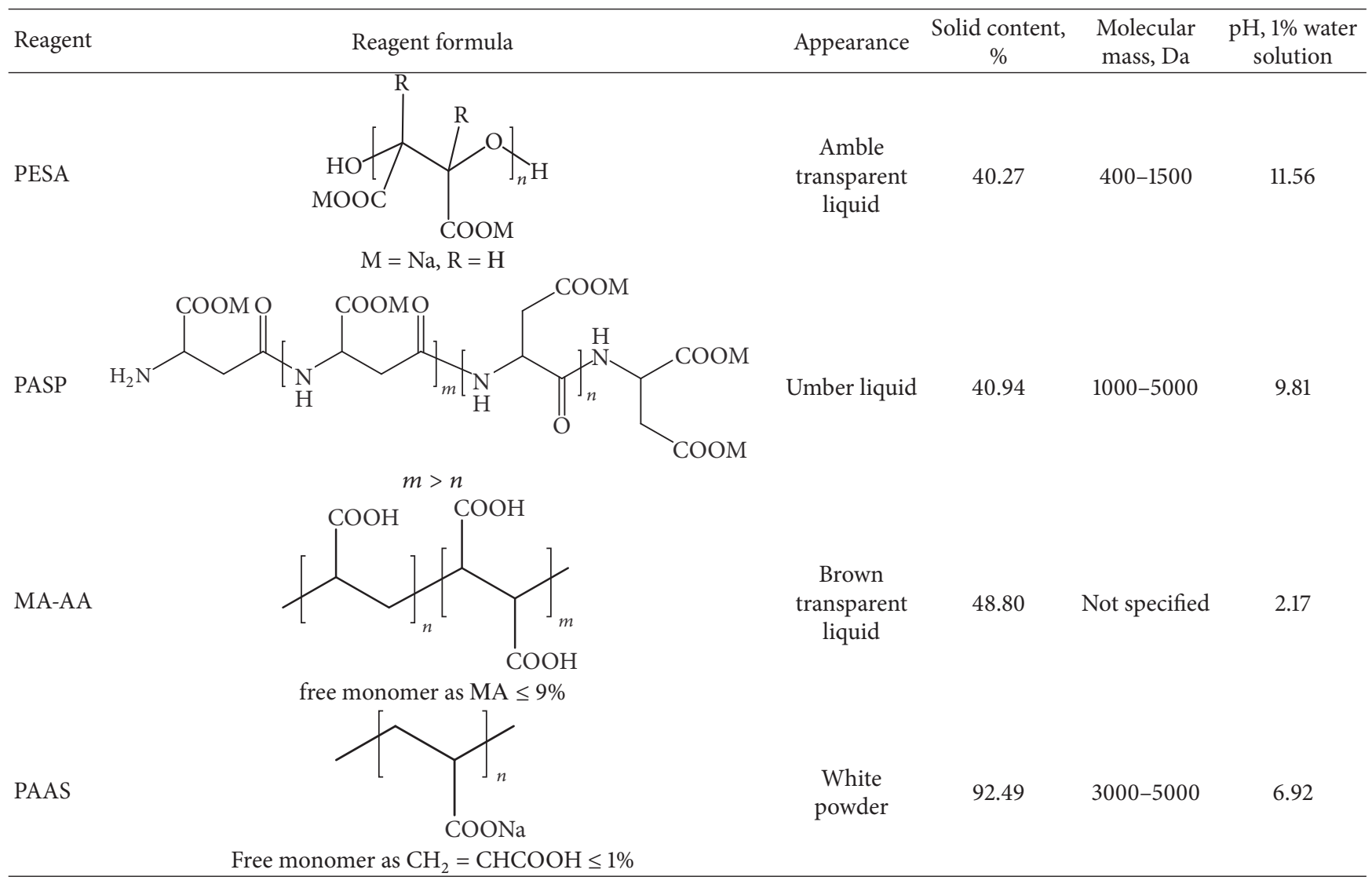

efficiency comparison [8-22]. Unfortunately, most of the data published on calcium sulfate deposition are considering a single antiscalant or a single group of similar reagents studied under hardly comparable conditions $[8-11,19,21,22]$, for example, different supersaturation index, brine composition, temperature, and measurement technique. Unfortunately, the comparative inhibitors performance ranking reports done by one and the same research group under uniform conditions are rather rare $[7,12-14,18,21,22]$.

At the same time, such rankings reveal frequently rather conflicting results. For example, different research groups report for calcium sulfate different antiscalant efficacy sequences. Particularly, for one and the same set of reagents, one group presents HEDP as the most efficient [12], while some others report it to be the least effective [22]. Meanwhile, for PBTC, both groups report a rather poor efficiency [12-14], while [18] indicates exactly PBTC as an antiscalant of choice for gypsum precipitation.

In this respect, a comparative performance of some traditional antiscalants (phosphonates, polyacrylates) and the novel environmentally friendly polymers (PASP, PESA) studied by a reliable method under comparable conditions becomes desirable. In the present work, the effects of industrial samples of four phosphorus-free polymers and of three phosphonates were tested with respect to their ability to inhibit calcium sulfate precipitation following NACE Standard [23]. Since it is anticipated that the inhibitors would cause changes of the surface charge of the calcium sulfate particles thus affecting their aggregation [20], then the zetapotential measurements by dynamic light scattering (DLS) technique were conducted along with scanning electron microscopy (SEM) and powder X-ray diffraction (XRD) studies of the solid phase equilibrating with colloidal solution. As far as we know, none of the antiscalants mentioned above was studied by NACE protocol for gypsum scale inhibition activity. At the same time, the supplementary details of a corresponding scale formation characterized by DLS, SEM, and XRD technique are also quite novel.

\section{Materials and Methods}

2.1. Materials. Polymer based industrial antiscalants, polyaspartic acid sodium salt (PASP), copolymer of maleic and acrylic acid (MA-AA), polyepoxysuccinic acid (PESA), and sodium salt of polyacrylic acid (PAAS), have been kindly supplied by Shandong Taihe Water Treatment Technologies Co., Ltd., and analyzed by NMR and dynamic light scattering technique (DLS). Table 1 lists the properties of polymers tested.

Industrial solid posphonates aminotris(methylenephosphonic acid), ATMP and 1-hydroxyethane-1,1-bis(phosphonic acid), and HEDP have been supplied by a manufacturer OAO "Khimprom," Novocheboksarsk, Russia. Both have been analyzed by NMR, found to have nearly reagent grade purity, and used without further purification. A liquid sample of 2-phosphonobutane 1,2,4-tricarboxylic acid (PBTC) is 
supplied by Shandong Taihe Water Treatment Technologies Co., Ltd. Polymer and phosphonate stock solutions were prepared on a dry weight basis. The desired concentrations of inhibitors were obtained by dilution.

${ }^{1} \mathrm{H},{ }^{31} \mathrm{P}$, and ${ }^{13} \mathrm{C}$ NMR measurements of polymer and phosphonate aqueous solutions were recorded with Bruker AVANCE II 300 spectrometer at ambient temperature in the $5 \mathrm{~mm}$ diameter sample tubes. The external standard solutions of TMS $\left({ }^{1} \mathrm{H},{ }^{13} \mathrm{C}\right)$ or phosphoric acid $\left({ }^{31} \mathrm{P}\right)$ were placed in a $1 \mathrm{~mm}$ inner coaxial tube.

For brine preparations, the analytical grade chemicals were used. Stock solutions of calcium chloride, sodium carbonate, and disodium sulfate were prepared from the respective crystalline solids (Aldrich; EKOS-1) using distilled water, filtered through a $0.22 \mu \mathrm{m}$ filter paper and standardized as described in [23].

2.2. Inhibition Evaluation Protocol. Inhibition tests were run following the NACE Standard TM0374-2007 protocol [23]. Two synthetic brines were prepared with distilled water: calcium-containing brine $\left(11.10 \mathrm{~g} \cdot \mathrm{dm}^{-3} \mathrm{CaCl}_{2} \cdot 2 \mathrm{H}_{2} \mathrm{O}\right.$ and $\left.7.50 \mathrm{~g} \cdot \mathrm{dm}^{-3} \mathrm{NaCl}\right)$ and sulfate-containing brine $\left(10.66 \mathrm{~g} \cdot \mathrm{dm}^{-3}\right.$ $\mathrm{Na}_{2} \mathrm{SO}_{4}$ and $\left.7.50 \mathrm{~g} \cdot \mathrm{dm}^{-3} \mathrm{NaCl}\right)$. Being mixed at $1: 1$ volume ratio, these brines give a supersaturated calcium sulfate solution with $\mathrm{pH}$ ranging from 6 to $7: 0.038 \mathrm{~mol} \cdot \mathrm{dm}^{-3}$ $\mathrm{CaCl}_{2} \cdot 2 \mathrm{H}_{2} \mathrm{O}, 0.038 \mathrm{~mol} \cdot \mathrm{dm}^{-3} \mathrm{Na}_{2} \mathrm{SO}_{4}$, and $0.128 \mathrm{~mol} \cdot \mathrm{dm}^{-3}$ $\mathrm{NaCl}$. By the end of the precipitation process, the ionic strength of this solution was around $0.2 \mathrm{~mol} \cdot \mathrm{dm}^{-3}$, provided mostly by $\mathrm{NaCl}$, and with activity coefficients $\gamma_{ \pm}=0.771$ [24].

A supersaturated solution of calcium sulfate with a calculated amount of inhibitor (from 0.5 to $15 \mathrm{mg} \cdot \mathrm{dm}^{-3}$ for polymers and from 0.5 to $3 \mathrm{mg} \cdot \mathrm{dm}^{-3}$ for phosphonates) was then kept for 24 hours at $71^{\circ} \mathrm{C}$, cooled, and analyzed for residual calcium content by EDTA titration. The $\mathrm{pH}$ of the solutions at $25^{\circ} \mathrm{C}$ was about 6 to 7 . All experiments were run in duplicate.

The performance of the tested compounds as calcium sulfate was calculated as inhibition percent $(I, \%)$ :

$$
\begin{aligned}
& \text { Percent inhibition }(I, \%) \\
& =100 \times \frac{[\mathrm{Ca}] \exp -[\mathrm{Ca}] \text { final }}{[\mathrm{Ca}] \text { init }-[\mathrm{Ca}] \text { final }}
\end{aligned}
$$

where [Ca] exp is the concentration of calcium in the filtrate in the presence of an inhibitor at 24 hours, [Ca] final is the concentration of calcium in the filtrate in the absence of an inhibitor at 24 hours, and [Ca] init is the concentration of calcium at the beginning of the experiment.

At the end of experiments, solid samples of precipitates if any were collected for characterization by powder Xray diffraction (XRD) and by scanning electron microscopy (SEM). Besides, the liquid phase was monitored by DLS technique after heating. The corresponding data are presented in Tables 2, 3, 4, and 5 and Figures 1, 2, and 3.

2.3. Crystal Characterization. The precipitated solids, after being triply rinsed with deionised water and air drying at
TABLE 2: Inhibitor relative performance $(I, \%)$ in a NACE calcium sulfate supersaturated solution.

\begin{tabular}{lccc}
\hline \multirow{2}{*}{ Inhibitor } & Final solution $\mathrm{pH}$ & 0.5 & 3.0 \\
& & \multicolumn{2}{c}{$I, \%^{*}$} \\
\hline PASP & 6.3 & $81 \pm 2$ & $100 \pm 2$ \\
PESA & 6.1 & $90 \pm 3$ & $100 \pm 2$ \\
MA-AA & 6.4 & $100 \pm 2$ & $100 \pm 2$ \\
PAAS & 6.3 & $43 \pm 2$ & $100 \pm 2$ \\
ATMP & 6.0 & $100 \pm 2$ & $100 \pm 2$ \\
PBTC & 6.0 & $41 \pm 4$ & $78 \pm 5$ \\
HEDP & 5.9 & $40 \pm 4$ & $52 \pm 3$ \\
\hline
\end{tabular}

${ }^{*}$ Mean arithmetic values from two replicate runs.

$50^{\circ} \mathrm{C}$, were characterized by scanning electron microscopy (SEM, Hitachi TM-3030) and powder X-ray diffraction (XRD, Bruker D8 Advance diffractometer; $\mathrm{Cu} \mathrm{K} \alpha$; Ni-filter; LYNXEYE detector). The XRD phase identification was done with JCPDS data base, and relative phase content was estimated with Topaz $\mathrm{R}$ software (Bruker AXS). The sample examinations by SEM were done at $15 \mathrm{kV}$ accelerating voltage in a Charge-Up Reduction Mode with crystal phase located on a Conducting Double-Sided Tape and the working distance $4.1 \mathrm{~mm}$.

2.4. Liquid Phase Characterization. Liquid phase was monitored by the dynamic light scattering (DLS) technique. DLS experiments were performed at $25^{\circ} \mathrm{C}$ with Malvern Nano ZS instrument $(\lambda=633 \mathrm{~nm}$, operating power $4 \mathrm{mVt})$ at $\Theta=173^{\circ}$. The refractive index $n$ (1.3397), the viscosity $\eta$ $(1123,0 \mu \mathrm{Pa})$, and the density $d\left(1,062 \mathrm{~g} \cdot \mathrm{dm}^{-3}\right)$ of $0.2 \mathrm{~mol} \cdot \mathrm{dm}^{-3}$ $\mathrm{NaCl}$ aqueous solution were measured and used to characterize the solvent. All the antiscalant solutions were clarified by $0.45 \mu \mathrm{m}$ Millipore Nylon filters to remove dust and checked by DLS technique for a presence of nanoparticles. The same operation was done with calcium and carbonate solutions before they have been mixed. The samples of calcium sulfate saturated solutions as well as calcium-free samples of all polymers used were analyzed for solid phase particle size and $\zeta$-potential directly after 24 hours of thermal treatment and cooling, 4 hours after cooling, and 24 hours after cooling.

\section{Results and Discussion}

3.1. Relative Inhibition Efficiency Evaluation. After calcium and sulfate brines are mixed in the blank experiment (without antiscalant) at $25^{\circ} \mathrm{C}$, no visual formation of a solid phase is observed. Only after 24 hours of treatment at $71^{\circ} \mathrm{C}$ and a subsequent cooling up to $25^{\circ} \mathrm{C}$, the solution turbidity occurs and increases with time. However, the EDTA titration performed immediately after cooling indicates that almost $75 \%$ of the initial calcium content still remains in a liquid phase. Thus, the solid phase formation process is spread over a substantial period of time, and that leads to undesirable differences in duplicate titrations and increases the experimental error. 
TABLE 3: Scale inhibitors ranking reports for calcium sulfate.

\begin{tabular}{|c|c|c|c|}
\hline Experiment details ${ }^{*}$ & $\begin{array}{l}\text { Dosage, } \\
\mathrm{mg} \cdot \mathrm{dm}^{-3}\end{array}$ & Ranking & Reference \\
\hline $\begin{array}{l}\text { Static method. Brine composition: } \mathrm{CaCl}_{2} \cdot 2 \mathrm{H}_{2} \mathrm{O} 6,8 \mathrm{~g} \cdot \mathrm{dm}^{-3} \\
\left(0,097 \mathrm{~mol} \cdot \mathrm{dm}^{-3}\right) ; \mathrm{Na}_{2} \mathrm{SO}_{4} 7,1 \mathrm{~g} \cdot \mathrm{dm}^{-3}\left(0.074 \mathrm{~mol} \cdot \mathrm{dm}^{-3}\right) ; \mathrm{pH}=7 ; 6 \\
\text { hours at } 70^{\circ} \mathrm{C}\end{array}$ & 5 & $\begin{array}{l}\mathrm{PA}(3500 \mathrm{Da})>\mathrm{HMP}>\mathrm{PA}(10000 \mathrm{Da}) \\
>\mathrm{PBTC}>\mathrm{HEDP}>\mathrm{PA}(50000 \mathrm{Da})\end{array}$ & {$[12]$} \\
\hline $\begin{array}{l}\text { Dynamic method: induction period and crystal growth velocity. } \\
\text { Brine composition: } \mathrm{CaSO}_{4} 0,0497 \mathrm{~mol} \cdot \mathrm{dm}^{-3} ; \mathrm{NaCl} 0.4 \mathrm{~mol} \cdot \mathrm{dm}^{-3} \text {; } \\
\mathrm{pH}=7 ; 25^{\circ} \mathrm{C}\end{array}$ & 0.5 & $\begin{array}{l}\mathrm{PA}(3500 \mathrm{Da})>\mathrm{HMP}>\mathrm{PA}(10000 \mathrm{Da}) \\
>\mathrm{PBTC}>\mathrm{HEDP}>\mathrm{PA}(50000 \mathrm{Da})\end{array}$ & {$[13]$} \\
\hline $\begin{array}{l}\text { Static method. Brine composition: }\left[\mathrm{Ca}^{2+}\right] 2,0 \mathrm{~g} \cdot \mathrm{dm}^{-3} \\
\left(0,097 \mathrm{~mol} \cdot \mathrm{dm}^{-3}\right),\left[\mathrm{SO}_{4}{ }^{2-}\right] 4,8 \mathrm{~g} \cdot \mathrm{dm}^{-3}\left(0,05 \mathrm{~mol} \cdot \mathrm{dm}^{-3}\right) \mathrm{pH} 7 ; 18 \\
\text { hours at } 60^{\circ} \mathrm{C}\end{array}$ & 5 & $\operatorname{PASP}(1-5 \mathrm{kDa})>\operatorname{PESA}(0,4-1,5 \mathrm{kDa})$ & {$[15]$} \\
\hline \multirow{2}{*}{$\begin{array}{l}\text { Static method. Brine composition: }\left[\mathrm{Ca}^{2+}\right] 0,097 \mathrm{~mol} \cdot \mathrm{dm}^{-3},\left[\mathrm{SO}_{4}{ }^{2-}\right] \\
0.074 \mathrm{~mol} \cdot \mathrm{dm}^{-3} ; \mathrm{pH}=7 ; 10 \text { hours at } 60^{\circ} \mathrm{C}\end{array}$} & 1 & $\begin{array}{l}\text { PMA }(600 \mathrm{Da})>\text { PA }(1800 \mathrm{Da})> \\
\text { PESA }(1500 \mathrm{Da})\end{array}$ & \multirow{2}{*}[9]{} \\
\hline & 5 & $\begin{array}{l}\text { PMA }(600 \mathrm{Da}) \sim \mathrm{PA}(1800 \mathrm{Da})> \\
\text { PESA }(1500 \mathrm{Da})\end{array}$ & \\
\hline $\begin{array}{l}\text { Static method. Brine composition: }\left[\mathrm{Ca}^{2+}\right] 6,8 \mathrm{~g} \cdot \mathrm{dm}^{-3} \\
\left(0.17 \mathrm{~mol} \cdot \mathrm{dm}^{-3}\right),\left[\mathrm{SO}_{4}{ }^{2-}\right] 7,1 \mathrm{~g} \cdot \mathrm{dm}^{-3}\left(0.07 \mathrm{~mol} \cdot \mathrm{dm}^{-3}\right), \mathrm{pH}=7 ; 10 \\
\text { hours at } 60^{\circ} \mathrm{C}\end{array}$ & 2 & $\begin{array}{l}\text { PBTC }>\text { PAA }(1800 \mathrm{Da})> \\
\text { PESA }(1500 \mathrm{Da})>\mathrm{HEDP}\end{array}$ & {$[18]$} \\
\hline $\begin{array}{l}\text { Static method. Brine composition: } \mathrm{CaSO}_{4} 0,045 \mathrm{~mol} \cdot \mathrm{dm}^{-3}, \mathrm{pH}= \\
7 ; 24 \text { hours at } 66^{\circ} \mathrm{C}\end{array}$ & 1 & $\begin{array}{l}\text { PA }(2000 \mathrm{Da})>\text { ATMP }>\text { PBTC }> \\
\text { HEDP }\end{array}$ & {$[14]$} \\
\hline $\begin{array}{l}\text { Static method. Brine composition: } \mathrm{CaSO}_{4} 0,0045 \mathrm{~mol} \cdot \mathrm{dm}^{-3}, \mathrm{pH}= \\
7 ; 20 \text { hours at } 66^{\circ} \mathrm{C}\end{array}$ & 2 & ATMP $>$ PA $(6 \mathrm{kDa})>$ PBTC $>$ HEDP & {$[17]$} \\
\hline $\begin{array}{l}\text { Static method. Brine composition: }\left[\mathrm{Ca}^{2+}\right] 0,097 \mathrm{~mol} \cdot \mathrm{dm}^{-3},\left[\mathrm{SO}_{4}{ }^{2-}\right] \\
0.074 \mathrm{~mol} \cdot \mathrm{dm}^{-3} ; \mathrm{pH}=7 ; 6 \text { hours at } 80^{\circ} \mathrm{C}\end{array}$ & 2 & PMA $(600 \mathrm{Da})>\mathrm{PA}(1800 \mathrm{Da})$ & {$[16]$} \\
\hline $\begin{array}{l}\text { Static method. Brine composition: }\left[\mathrm{Ca}^{2+}\right] 0,097 \mathrm{~mol} \cdot \mathrm{dm}^{-3},\left[\mathrm{SO}_{4}{ }^{2-}\right] \\
0.074 \mathrm{~mol} \cdot \mathrm{dm}^{-3} ; \mathrm{pH}=7 ; 6 \text { hours at } 80^{\circ} \mathrm{C}\end{array}$ & 2 & $\begin{array}{l}\text { PA }(2000 \mathrm{Da})>\mathrm{PMA}(1000 \mathrm{Da})> \\
\mathrm{PA}(6000 \mathrm{Da})\end{array}$ & {$[20]$} \\
\hline $\begin{array}{l}\text { Dynamic method: crystal growth velocity at } 55^{\circ} \mathrm{C} \text {. Brine } \\
\text { composition: } 0.045 \mathrm{~mol} \cdot \mathrm{dm}^{-3} \mathrm{CaCl}_{2} \text { and } 0.045 \mathrm{~mol} \cdot \mathrm{dm}^{-3} \mathrm{Na}_{2} \mathrm{SO}_{4}\end{array}$ & 1 & $\begin{array}{l}\text { PASP efficacy is comparable with } \\
\text { industrial phosphonates }\end{array}$ & [7] \\
\hline \multirow{2}{*}{$\begin{array}{l}\text { Static method. Brine composition: } \mathrm{CaCl}_{2} \cdot 2 \mathrm{H}_{2} \mathrm{O} 6,8 \mathrm{~g} \cdot \mathrm{dm}^{-3} \\
\left(0,097 \mathrm{~mol} \cdot \mathrm{dm}^{-3}\right) ; \mathrm{Na}_{2} \mathrm{SO}_{4} 7,1 \mathrm{~g} \cdot \mathrm{dm}^{-3}\left(0.074 \mathrm{~mol} \cdot \mathrm{dm}^{-3}\right) ; \mathrm{pH}=7 ; 10 \\
\text { hours at } 60^{\circ} \mathrm{C}\end{array}$} & 3 & $\begin{array}{l}\text { PA }(1800 \mathrm{Da})>\text { PMA }(600 \mathrm{Da})> \\
\text { PESA }(1500 \mathrm{Da})\end{array}$ & \multirow{2}{*}[21]{} \\
\hline & 9 & $\begin{array}{l}\text { PESA }(1500 \mathrm{Da}) \geq \mathrm{PA}(1800 \mathrm{Da}) \geq \\
\text { PMA }(600 \mathrm{Da})\end{array}$ & \\
\hline $\begin{array}{l}\text { Static method. Brine composition: }\left[\mathrm{Ca}^{2+}\right] 0,051 \mathrm{~mol} \cdot \mathrm{dm}^{-3},\left[\mathrm{SO}_{4}{ }^{2-}\right] \\
0.021 \mathrm{~mol} \cdot \mathrm{dm}^{-3} ; 10 \text { hours at } 80^{\circ} \mathrm{C}\end{array}$ & 5 & PASP $>$ PESA > HEDP & {$[22]$} \\
\hline \multirow[t]{2}{*}{$\begin{array}{l}\text { Static method. Brine composition: } \mathrm{CaCl}_{2} \cdot 2 \mathrm{H}_{2} \mathrm{O} 5,55 \mathrm{~g} \cdot \mathrm{dm}^{-3} \\
\left(0,038 \mathrm{~mol} \cdot \mathrm{dm}^{-3}\right), \mathrm{Na}_{2} \mathrm{SO}_{4} 5,33 \mathrm{~g} \cdot \mathrm{dm}^{-3}\left(0.038 \mathrm{~mol} \cdot \mathrm{dm}^{-3}\right) ; \mathrm{NaCl} \\
7,50 \mathrm{~g} \cdot \mathrm{dm}^{-3}\left(0.11 \mathrm{~mol} \cdot \mathrm{dm}^{-3}\right) \mathrm{pH}=6-7 ; 24 \text { hours at } 71^{\circ} \mathrm{C}\end{array}$} & 0.5 & $\begin{array}{l}\text { MA-AA } \sim \text { ATMP }>\text { PESA }(400- \\
1500 \text { Da })>\text { PASP }(1000-5000 \text { Da }) \\
>\text { PAAS }(3000-5000 \text { Da }) \sim \text { HEDP } \sim \\
\text { PBTC }\end{array}$ & \multirow[t]{2}{*}{ Our data } \\
\hline & 3.0 & $\begin{array}{l}\text { PAAS }(3000-5000 \mathrm{Da})>\mathrm{HEDP}> \\
\text { PBTC }\end{array}$ & \\
\hline
\end{tabular}

*For static methods, an antiscaling effect was estimated by calcium titration with EDTA before and after deposition.

TABLE 4: DLS calcium sulfate particles characterization in an aqueous phase at $25^{\circ} \mathrm{C}$ directly after cooling of a supersaturated gypsum solution.

\begin{tabular}{|c|c|c|c|c|c|c|}
\hline Scale inhibitor & Blank & PBTC & MA-AA & PASP & ATMP & HEDP \\
\hline Inhibitor dosage, $\mathrm{mg} \cdot \mathrm{dm}^{-3}$ & 0 & 0.5 & 0.5 & 0.5 & 0.5 & 0.5 \\
\hline $\mathrm{pH}$ & 6.20 & 6.02 & 6.39 & 6.30 & 5.95 & 5.88 \\
\hline Ionic strength, $\mathrm{mol} \cdot \mathrm{dm}^{-3}$ & 0.2 & 0.2 & 0.2 & 0.2 & 0.2 & 0.2 \\
\hline Scale inhibition, \% & 0 & 41 & 100 & 81 & 100 & 40 \\
\hline Number of fractions (by volume) & 1 & 2 & 1 & 1 & 2 & 3 \\
\hline $\begin{array}{l}\text { Mean hydrodynamic diameter (by } \\
\text { volume) }{ }^{\mathrm{a}}, \mathrm{nm}\end{array}$ & $150(50)^{\mathrm{b}}$ & $\begin{array}{c}50(20) \\
400(100)\end{array}$ & $500(90)$ & $330(70)$ & $\begin{array}{c}60(20) \\
300(80)\end{array}$ & $\begin{array}{c}50(20) \\
730(100) \\
5000(1000)\end{array}$ \\
\hline$\zeta$-Potential ${ }^{\mathrm{a}}, \mathrm{mV}$ & $-2.4(0.1)$ & $-3.9(0.1)$ & $-1.5(0.1)$ & $-7.0(0.8)$ & $-0.6(0.1)$ & $-1.0(0.2)$ \\
\hline
\end{tabular}

${ }^{\mathrm{a}}$ Data in parentheses represent standard deviation for three replicate runs.

${ }^{\mathrm{b}}$ Monotonous colloidal particles growth takes place. 
TABLE 5: Mean hydrodynamic diameter of calcium sulfate particles dependence on time at $25^{\circ} \mathrm{C}$.

\begin{tabular}{|c|c|c|c|c|}
\hline \multirow{2}{*}{$\begin{array}{l}\text { Scale } \\
\text { inhibitor }\end{array}$} & \multirow{2}{*}{$\begin{array}{l}\text { Dosage, } \\
\mathrm{mg} \cdot \mathrm{dm}^{-3}\end{array}$} & \multicolumn{3}{|c|}{$\begin{array}{l}\text { Mean hydrodynamic diameter (by } \\
\text { volume), nm }\end{array}$} \\
\hline & & 0 hours & 4 hours & 24 hours \\
\hline None & 0 & 150 & 300 & $\begin{array}{c}500 \\
4000\end{array}$ \\
\hline MA-AA & 0.5 & 500 & 400 & 400 \\
\hline ATMP & 0.5 & $\begin{array}{c}60 \\
300 \\
\end{array}$ & $\begin{array}{c}200 \\
4000 \\
\end{array}$ & $\begin{array}{c}300 \\
5000 \\
\end{array}$ \\
\hline PBTC & 0.5 & $\begin{array}{c}50 \\
400\end{array}$ & $\begin{array}{c}400 \\
4000\end{array}$ & $\begin{array}{c}60 \\
400 \\
4000\end{array}$ \\
\hline
\end{tabular}

MA-AA ATMP > PESA $(400-1500 \mathrm{Da})>\operatorname{PASP}(1000-5000 \mathrm{Da}) \gg$ PAAS $(3000-5000 \mathrm{Da}) \sim \mathrm{PBTC} \sim \mathrm{HEDP}$.
Implementation of inhibitor increases liquid phase calcium content up to $100 \%$. Figure 1 demonstrates that all four polymers reveal an increasing inhibition performance as the dosage is changed from 0.5 to $15 \mathrm{mg} \cdot \mathrm{dm}^{-3}$. At the same time, when reagent concentration exceeds $1 \mathrm{mg} \cdot \mathrm{dm}^{-3}$, then the efficacy becomes dosage-independent. The constancy indicates that $100 \%$ efficiency is achieved.

ATMP exhibits the same inhibition efficacy as the best one of polymers studied (MA-AA) (Table 2). Meanwhile, for HEDP and PBTC, the maximal efficacy does not exceed 60 and $80 \%$, respectively, when inhibition becomes dosageindependent. Thus, PBTC reveals generally better performance than HEDP, although both phosphonates are the least effective among the reagents tested (Table 2). The differences an antiscalant content, the following ranking is obtained: between polymers get visible at $0.5 \mathrm{mg} \cdot \mathrm{dm}^{-3}$ dosage. For such
For $3 \mathrm{mg} \cdot \mathrm{dm}^{-3}$ reagent dosage, a further differentiation between PAAS (3000-5000 Da), HEDP, and PBTC becomes possible: PAAS (3000-5000 Da) > PBTC > HEDP.

In Table 3, our ranking is presented along with literature data $[7,9,12-18,20-22]$. Surprisingly, the results of all known comparative studies of the inhibitor efficiency are obtained under different experimental conditions and none of them follow NACE protocol. Our evaluation agrees with sequence reported by [12-14], polyacrylate PAAS (3000-5000 Da) > PBTC > HEDP, and with those presented in [19], ATMP > HEDP as well as in [22], PESA > HEDP. At the same time, it is in some disagreement with $[15,22]$ concerning PASP/PESA relative efficiency.

This inconsistence however can be attributed to the different molecular mass of PASP and PESA used in [15, 22] and in the present work. Meanwhile, our data do not conform to the conclusions concerning HEDP [12] and PBTC [18] preference over PESA (1500 Da) and PA (1800 Da). A possible explanation of the conflicting results may be attributed to the different quality of industrial polymers produced by different manufacturers. Each polymer sample contains according to NMR analysis a certain amount of monomers and byproducts which give no contribution to the inhibition effect but might be erroneously treated as active ingredients under "total solid phase content," specified normally by the manufacturer. Different samples of one and the same polymer with the same molecular mass and the same total solid phase content therefore may have different active substance content and reveal different efficacy. Unfortunately, most of the manufacturers do not differentiate the "total solid phase content" and "active solid phase content." Usually, this is not the case of phosphonates, which have normally much less impurities, such as phosphoric or phosphinic acids.

However, 20 years ago, we have tested seven industrial samples of HEDP present at Russian market and registered for all of them an impurity of the ball-shaped tetramer of HEDP, which had a zero inhibitory activity. Moreover, for the two lots among these, the tetramer content exceeded $30 \%$ of the total phosphorus, claimed as HEDP [25]. Our critical analysis of phosphonates dated 2001 indicated also that such a reagent as diethylenetriaminepenta(methylenephosphonic acid) (DTPH) might have more phosphorus rather as the byproducts than as DTPH itself [26]. Thus, for the pair "phosphonates/phosphorus-free polymers," the conflicting results may arise from different reagent quality. Unfortunately, up to now, none of the papers published have considered the reagent quality.

Generally, the efficiency of the "green" regents PESA (400-1500 Da) and PASP (1000-5000 Da) is very close to that of a traditional phosphonate ATMP and to a novel phosphorus-free MA-AA (Table 2). At the same time, PESA and PASP demonstrate much better activity than a traditional polyacrylate (PAAS), PBTC, and HEDP as far as gypsum scale is concerned.

Meanwhile, the NACE protocol ranking of the same reagents for calcium carbonate scaling gives a bit different sequence [27]:

$$
\text { ATMP > HEDP > PESA }(400-1500 \mathrm{Da}) \sim \text { PASP }(1000-5000 \mathrm{Da})>\text { PAAS }(3000-5000 \mathrm{Da}) \sim \mathrm{MA}-\mathrm{AA}
$$

A comparison of (2) and (3) indicates that ATMP is one of the best reagents for both carbonate and sulfate fouling, while MA-AA and HEDP efficiency are strongly dependent on the scale chemistry. "Green" antiscalants PESA 


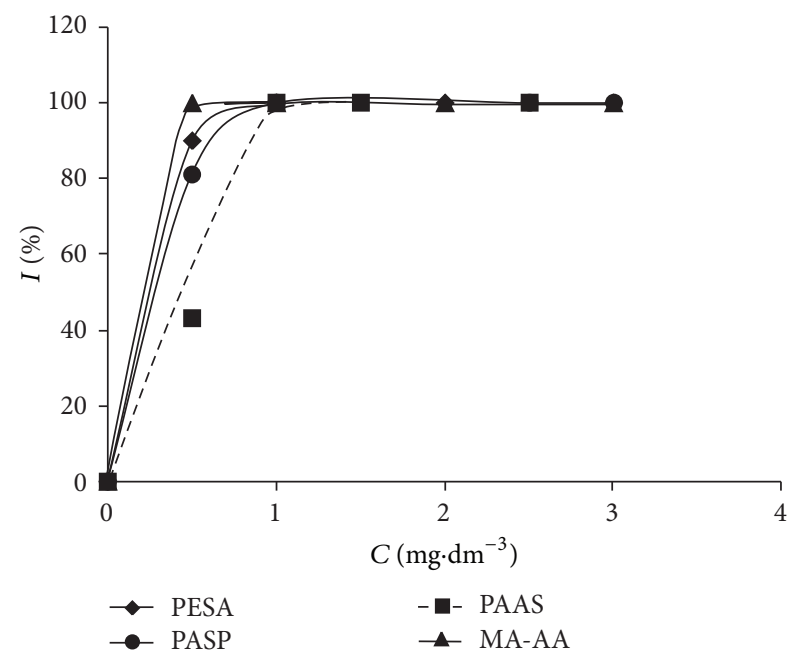

FIGURE 1: Inhibition of calcium sulfate precipitation in the presence of varying concentration $(C)$ of inhibitor after 24 hours treatment.

and PASP also reveal good activity toward both carbonate and sulfate deposits. However, the NACE protocol deals either with calcium carbonates or with calcium sulfates, while the sea water used in RO technologies has both these salts present.

Therefore, NACE testament as well as any other laboratory-scale evaluation seems to be an important but a very preliminary test to be verified by a test under real RO conditions. A comparison of NACE protocol antiscalant rankings with those obtained in $\mathrm{RO}$ experiments is now a matter of our separate publication, which is now in press.

\subsection{Solid Phase Characterization by XRD and SEM. A set} of experiments with an antiscalant dosage of $0.5 \mathrm{mg} \cdot \mathrm{dm}^{-3}$ was chosen for equilibrating liquid and solid phases characterization as far as it was possible to isolate some crystals for this dosage of PESA, PASP, PAAS, HEDP, and PBTC. The precipitated phases in all cases are identified by XRD as gypsum. Indeed, at ambient temperatures of $20^{\circ} \mathrm{C}$, gypsum is the most common form [28]. This result is consistent with those found earlier for calcium sulfate supersaturated solution [11, 28].

The crystal morphology of $\mathrm{CaSO}_{4} \cdot 2 \mathrm{H}_{2} \mathrm{O}$ depends on the supersaturating ratio and crystallization kinetics. Needle-like crystals were noticed to be generated under conditions of low supersaturation ratio $S<2.27$, dominated by surface crystallization and characterized by a lengthy induction time prior to nucleation. On the other hand, plate-like morphology is observed at a supersaturation ratio of 10.86 , dominated by bulk crystallization [28]. Indeed, for our blank experiment without inhibitor and for those run in the presence of PESA, PASP, PAAS, and HEDP, the SEM images indicate needle-like crystals (Figure 2). Evidently, these antiscalants get adsorbed onto gypsum surface. PESA, PASP, and PAAS provide the visible pitting-like spots on the gypsum crystal surface but change neither crystallographic form nor the morphology of gypsum crystals. The gypsum crystals isolated from HEDP solutions had no pits and do not seem to differ from those obtained in a blank experiment.

Surprisingly, PBTC reveals a different behavior (Figure 3), demonstrating a capability to change the morphology of gypsum crystals up to a completely irregular shape. We have run six replicates of a NACE test with $0.5 \mathrm{mg} \cdot \mathrm{dm}^{-3}$ dosages. All six experiments with PBTC gave crystals without pits, but with significantly shortened needles, while two revealed the form, presented in Figures 3(a) and 3(d).

Actually, the modification of crystal morphology and even of the crystallographic form by an antiscalant is well known [11, 27, 29]. Moreover, this change of crystal morphology is usually interpreted as a direct approval of the inhibition mechanism, which supposes a decreased growth rate of the deposited crystals by blocking the active sites of growth by an antiscalant molecule [29-31].

In this relevance, one could expect that the most effective antiscalant should cause the maximal distortion, while the least effective would reveal the minimal change in crystal morphology if any. In our case, the more effective antiscalants PESA, PASP, and PAAS do not change the morphology of gypsum, while the less effective PBTC does. We have reproduced these SEM measurements several times and got the same result. As far as we know, this is the first observation of the "irregular" impact of antiscalants on the crystal morphology. Thus, some theoretical grounds need further improvement or revision in this respect.

3.3. DLS Liquid Phase Characterization. Along with a solid phase characterization, the DLS experiments with the liquid phase were performed (Tables 4 and 5). These experiments were run for a $0.5 \mathrm{mg} \cdot \mathrm{dm}^{-3}$ antiscalant dosage, which provides $100 \%$ (ATMP, MA-AA), $80 \%$ (PASP), or nearly $40 \%$ (PBCT, HEDP) inhibition. At this concentration level, neither MA-AA nor PASP exhibits any DLS-detectable selfassociated particles. Thus, the observed particles belong to the gypsum phase.

Each supersaturated calcium sulfate solution was tested after 24 hours of incubation at $71^{\circ} \mathrm{C}$ and a subsequent cooling of the sample to $25^{\circ} \mathrm{C}$. This point corresponds to the inhibition efficiency estimation by a NACE protocol. However, the two more additional measurements have been run with the same solutions: 4 hours later and 24 hours after the first measurement.

Immediately after cooling, a blank solution reveals the presence of monomodal calcium sulfate particles, characterized by a mean diameter of about $150 \mathrm{~nm}$, which changes rapidly within the next 4 hours up to $300 \mathrm{~nm}$, and a $\zeta$ potential of around $-2.4 \mathrm{mV}$ (Table 4 , Figure 4 ). This colloidal solution is very unstable and within the next 24 hours at ambient temperature the corresponding increase in solution turbidity, the scale mass, and particles hydrodynamic diameter up to $5000 \mathrm{~nm}$ is observed (Table 5).

At the same time, the size distribution becomes bimodal indicating two fractions with mean hydrodynamic diameter of 500 and $4000 \mathrm{~nm}$ (Figure 4). These data demonstrate that the initially formed particles grow monotonously in size due to the calcium and sulfate ions accumulation by gypsum crystal lattice of the crystallization centers that have initially 


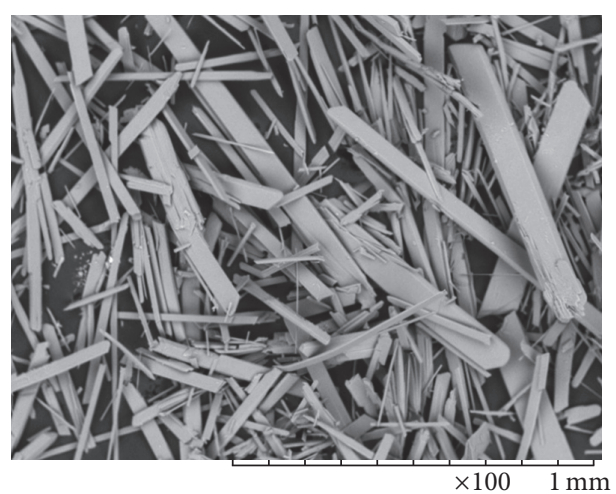

(a)

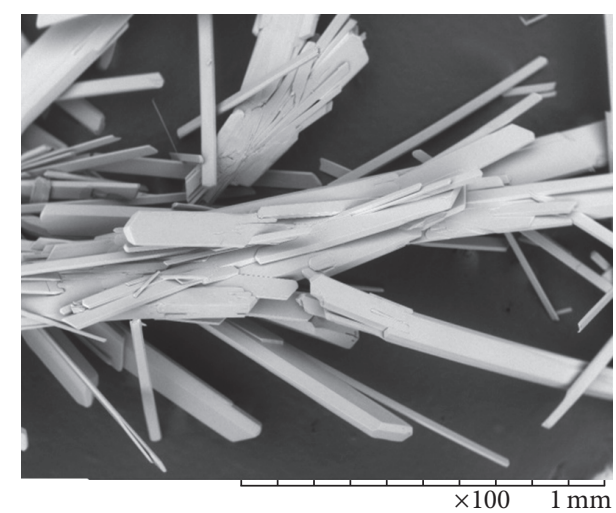

(c)

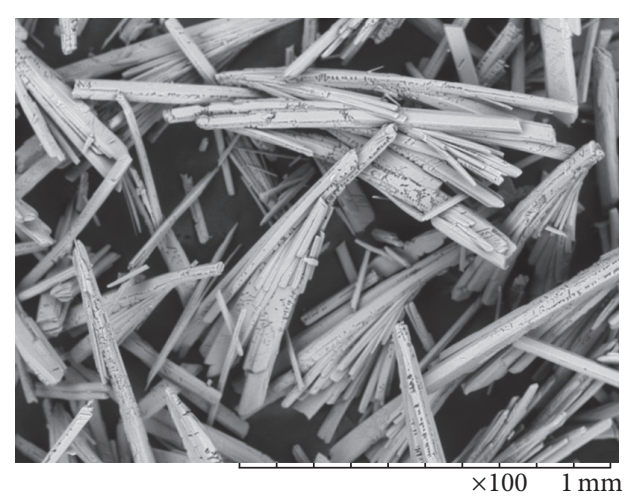

(b)

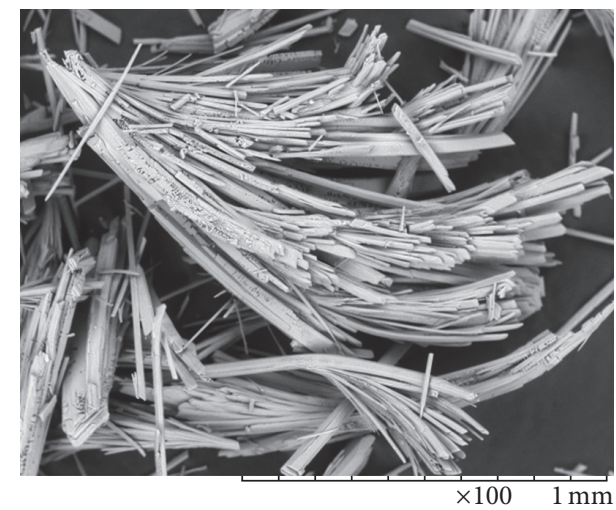

(d)

FIGURE 2: SEM images $(\times 100)$ of gypsum crystals isolated from a blank NACE solution (a) and from the brines in the presence of $0.5 \mathrm{mg} \cdot \mathrm{dm}{ }^{-3}$ PAAS (b), HEDP (c), and PASP (d).

formed in a supersaturated solution. After the particle size reach c.a. $500 \mathrm{~nm}$ level, then, an aggregation of these particles likely takes place, and a fraction with $4000 \mathrm{~nm}$ diameter occurs in an equilibrium with $500 \mathrm{~nm}$ diameter particles.

In presence of inhibitors, the DLS screening of gypsum supersaturated solutions indicates immediately after cooling a particle distribution, which is very similar to that observed for the blank solution (Table 4). For all the reagents studied, a formation of 300 to $700 \mathrm{~nm}$ diameter particles is registered with a miserably low negative $\zeta$-potential around $-2 \mathrm{mV}$. At the same time, there is no significant difference between "good" and "bad" inhibitors, and there is no definite correlation of a particle size or $\zeta$-potential with a scale inhibition efficiency. Indeed, for MA-AA and PASP, the monomodal volume distribution is observed with a mean particle diameter of 500 and $330 \mathrm{~nm}$ and $\zeta$-potential values of -1.5 and $-7.0 \mathrm{mV}$, respectively. For the phosphonates, either bimodal (PBTC, ATMP) or even three-modal (HEDP) particle size distribution from 50 to $700 \mathrm{~nm}$ is found. All these particles reveal very low $\zeta$-potential values.

As far as phosphonates are concerned, this result is a particular challenge for the theory: the observed $\zeta$-potentials are hardly capable of stabilizing the colloidal solution, which requires normally $30 \mathrm{mV} \leq \zeta$ or $\zeta \leq-30 \mathrm{mV}$ [32]. Therefore $\zeta$ $=-3 \mathrm{mV}$ is unable to provide any colloidal stability of calcium sulfate under the conditions of a NACE protocol. Evidently, none of the phosphonates studied reveal $\zeta$-potential higher than that found in a blank solution. At the same time, the phosphonate solutions reveal the presence of colloidal particles of a size similar to the blank solution. However, the NACE protocol reports equally a $100 \%$ inhibition for both MA-AA and ATMP and a nonzero inhibition for PBTC and HEDP.

A situation becomes more clear from the 24-hour DLS experiments. For MA-AA, the gypsum particles (i) do exist in the supersaturated gypsum solutions; (ii) do not aggregate irrespective of a very low electrostatic repulsion; and (iii) do not form any scale (100\% inhibition). Unlike MA-AA, ATMP reveals an increase of a mean particle size up to $5000 \mathrm{~nm}$ within 24 hours (Table 5, Figure 4). Thus, ATMP is surely a weaker inhibitor relative to MA-AA.

It should be noted that such an increase for all three phosphonates studied has a discrete character. Three fractions ranging from 50 to $70 \mathrm{~nm}$, from 300 to $500 \mathrm{~nm}$, and around $4000 \mathrm{~nm}$ exist in a semiequilibrium with one another. Meanwhile, an intensity of the bigger particles light scattering is steadily increasing with time, while for the smaller particles it is decreasing. Thus, the differences between the blank experiments and scaling in the presence of inhibitor might be explained by the different number of particles initially formed. In the latter case, the number of solid phase particles should be sufficiently less than those in a blank solution. 


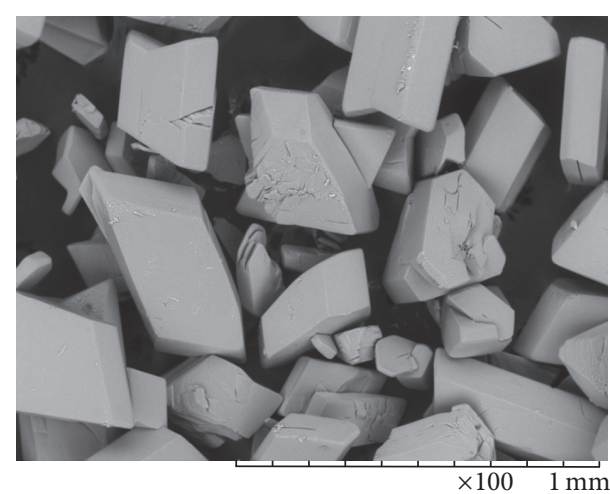

(a)

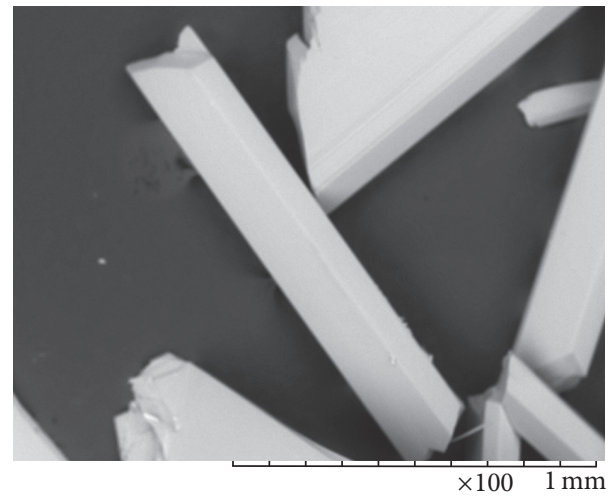

(c)

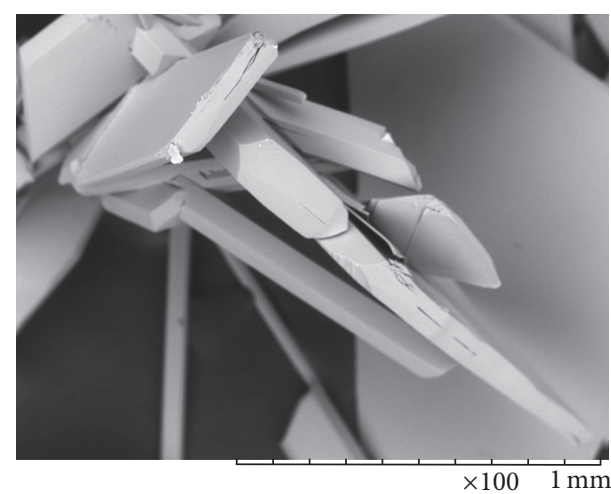

(b)

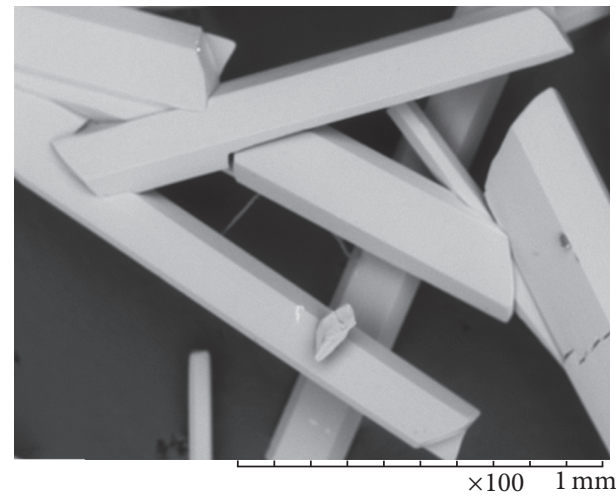

(d)

FIGURE 3: SEM images $(\times 100)$ of gypsum crystals isolated in different replicate runs from the gypsum brines in the presence of $0.5 \mathrm{mg} \cdot \mathrm{dm}^{-3}$ PBTC.

Thus, both the polymers and phosphonates studied prevent mostly the initial crystallization centers formation. However, an approval or disapproval of such a hypothesis requires further research.

\section{Conclusions}

A relative ability of the industrial samples of four phosphorus-free polymers (PASP, PESA, PAAS, and MA-AA) and of three phosphonates (ATMP, HEDP, and PBTC) to inhibit calcium sulfate precipitation is tested following the NACE Standard TM0374-2007 for the dosages 0.5 and $3.0 \mathrm{mg} \cdot \mathrm{dm}^{-3}$. For the dosage $0.5 \mathrm{mg} \cdot \mathrm{dm}^{-3}$, ATMP and MA-AA exhibited $100 \%$ inhibition, while PBTC and HEDP revealed the least efficacy around only 40\%. The following efficiency ranking MA-AA ATMP > PESA (400-1500 Da) > $\operatorname{PASP}(1000-5000 \mathrm{Da}) \gg \operatorname{PAAS}(3000-5000 \mathrm{Da}) \sim \mathrm{PBTC} \sim$ HEDP is found. Taking into account $1.0 \mathrm{mg} \cdot \mathrm{dm}^{-3}$ dosage data and DLS measurements, this ranking may be formulated more precisely: MA-AA > ATMP > PESA (400-1500 Da) > PASP (1000-5000 Da) $\gg$ PAAS (3000-5000 Da) > PBTC > HEDP. Thus, the maleic anhydride-based polymer is found to be the most effective for $\mathrm{CaSO}_{4}$ scaling system in static laboratory NACE testament conditions.

Analysis of publications on inhibiting impact of different antiscalants on the calcium sulfates deposition and of the existing laboratory reagent rankings reveals rather conflicting results. Such a diversity in antiscalants efficacy reports makes a choice of a proper reagent for a particular application rather difficult. It is stated that the grounds for that may be associated with unclear reagent formulations and nonuniform testament conditions (different $\left[\mathrm{SO}_{4}{ }^{2-}\right] /\left[\mathrm{Ca}^{2+}\right]$ molar ratios, different supersaturation indexes, different temperatures, treatment time, etc.). Thus, a widely accepted laboratory-scale inhibitors screening procedure is required and a large variety of empirical techniques to assist selection of suitable antiscalants for specific situations has to be developed.

A parallel study of the aqueous and solid gypsum phases in NACE brines by DLS, SEM, and XRD indicated that the observed colloidal stability in presence of phosphonates and polymers could not be attributed to either electrostatic stabilization or the crystal growth retardation. Indeed, the zeta-potentials for all reagents appeared to be insufficient to prevent gypsum particles aggregation. Meanwhile, it is found that those reagents that demonstrate a higher inhibition efficacy in a NACE brine do not change the morphology of gypsum, while the less effective PBTC does. As far as we know, this is the first observation of such "anomalous" impact of antiscalants on the crystal morphology. These facts support an opinion that the antiscalant activity mechanisms are still not yet clear $[29,33,34]$, and a further work is needed to reach a progress in this field. 

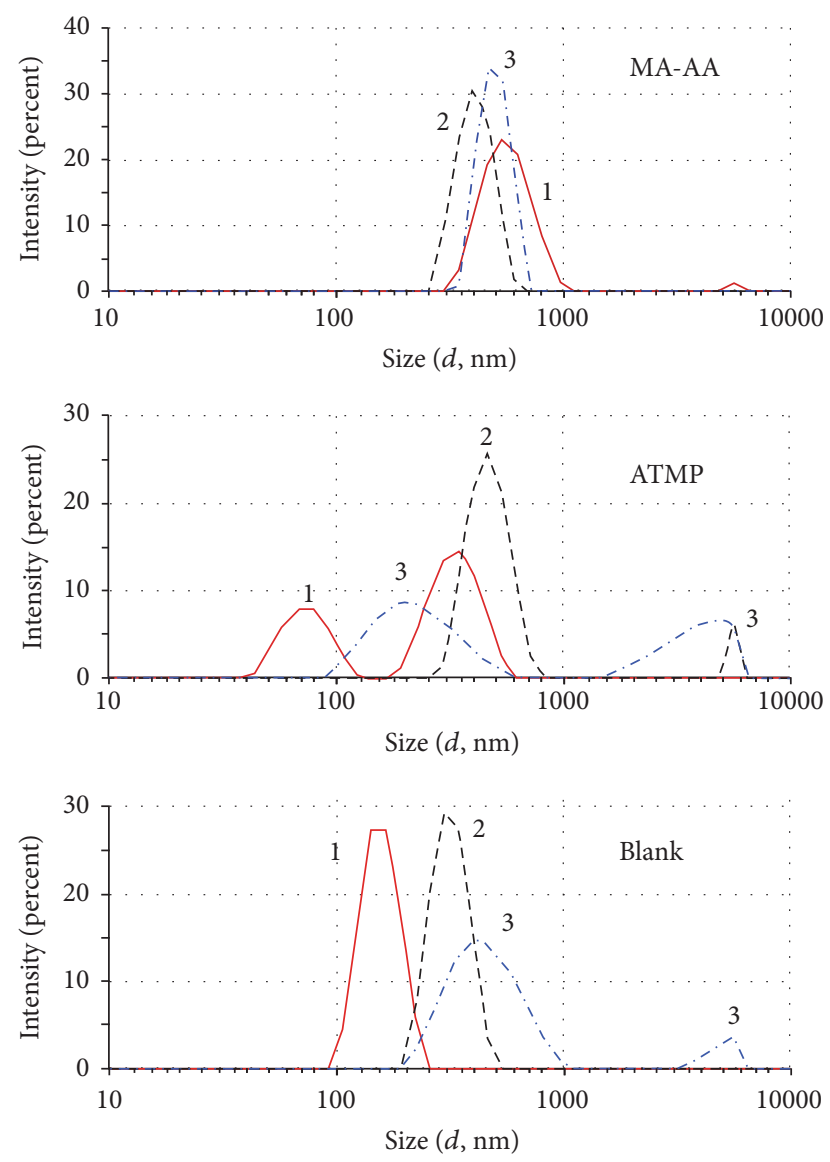

Figure 4: Gypsum particle size distribution by intensity for $0.5 \mathrm{mg} \cdot \mathrm{dm}^{-3}$ MA-AA, ATMP, and a blank solution measured by DLS technique immediately after cooling (1), after 4 hours (2), and after 24 hours (3).

\section{Competing Interests}

The authors declare that they have no competing interests.

\section{Acknowledgments}

This work was supported by the Ministry of Education and Science of the Russian Federation, Project ID RFMEFI58214X0007, Project no. 14.582.21.0007.

\section{References}

[1] Y. O. Rosenberg, I. J. Reznik, S. Zmora-Nahum, and J. Ganor, "The effect of $\mathrm{pH}$ on the formation of a gypsum scale in the presence of a phosphonate antiscalant," Desalination, vol. 284, pp. 207-220, 2012.

[2] Y. M. Al-Roomi and K. F. Hussain, "Application and evaluation of novel acrylic based $\mathrm{CaSO}_{4}$ inhibitors for pipes," Desalination, vol. 355, pp. 33-44, 2015.

[3] K. D. Demadis, E. Neofotistou, E. Mavredaki, M. Tsiknakis, E.-M. Sarigiannidou, and S. D. Katarachia, "Inorganic foulants in membrane systems: chemical control strategies and the contribution of 'green chemistry'" Desalination, vol. 179, no. 1-3, pp. 281-295, 2005.
[4] D. Hasson, H. Shemer, and A. Sher, "State of the art of friendly 'green' scale control inhibitors: a review article," Industrial and Engineering Chemistry Research, vol. 50, no. 12, pp. 7601-7607, 2011.

[5] "Scale Inhibitor Market by Type and by Application-Global Trends \& Forecast to 2019," http://www.researchandmarkets .com/reports/2933881/scale-inhibitor-market-by-type-and-byapplication\#\%20pos- 0 .

[6] M. Feiner, S. Beggel, N. Jaeger, and J. Geist, "Increased RO concentrate toxicity following application of antiscalantsacute toxicity tests with the amphipods Gammarus pulex and Gammarus roeseli," Environmental Pollution, vol. 197, pp. 309312, 2015.

[7] H. Shemer and D. Hasson, "Characterization of the inhibitory effectiveness of environmentally friendly anti-scalants," Desalination and Water Treatment, vol. 55, no. 13, pp. 3478-3484, 2015.

[8] S. A. Ali, I. W. Kazi, and F. Rahman, "Synthesis and evaluation of phosphate-free antiscalants to control $\mathrm{CaSO}_{4} \cdot 2 \mathrm{H}_{2} \mathrm{O}$ scale formation in reverse osmosis desalination plants," Desalination, vol. 357, pp. 36-44, 2015.

[9] H. Wang, G. Liu, J. Huang et al., "Performance of an environmentally friendly anti-scalant in $\mathrm{CaSO}_{4}$ scale inhibition," Desalination and Water Treatment, vol. 53, no. 1, pp. 8-14, 2015.

[10] M. Prisciandaro, E. Olivieri, A. Lancia, and D. Musmarra, "PBTC as an antiscalant for gypsum precipitation: interfacial tension and activation energy estimation," Industrial and Engineering Chemistry Research, vol. 51, no. 39, pp. 12844-12851, 2012.

[11] F. Rahman, "Calcium sulfate precipitation studies with scale inhibitors for reverse osmosis desalination," Desalination, vol. 319, pp. 79-84, 2013.

[12] Y. Liu, Y. Zhou, Q. Yao et al., "Double-hydrophilic polyether antiscalant used as a crystal growth modifier of calcium scales in cooling-water systems," Journal of Applied Polymer Science, vol. 131, no. 2, Article ID 39792, 2014.

[13] Z. Amjad, "Applications of antiscalants to control calcium sulfate scaling in reverse osmosis systems," Desalination, vol. 54, pp. 263-276, 1985.

[14] Z. Amjad, R. T. Landgraf, and J. L. Penn, "Calcium sulfate dihydrate (gypsum) scale inhibition by PAA, PAPEMP, and PAA/PAPEMP blend," International Journal of Corrosion and Scale Inhibition, vol. 3, no. 1, pp. 35-47, 2014.

[15] D. Liu, W. Dong, F. Li, F. Hui, and J. Lédion, "Comparative performance of polyepoxysuccinic acid and polyaspartic acid on scaling inhibition by static and rapid controlled precipitation methods," Desalination, vol. 304, pp. 1-10, 2012.

[16] C. Fu, Y. Zhou, G. Liu, J. Huang, W. Sun, and W. Wu, "Inhibition of $\mathrm{Ca}_{3}\left(\mathrm{PO}_{4}\right)_{2}, \mathrm{CaCO}_{3}$, and $\mathrm{CaSO}_{4}$ precipitation for industrial recycling water," Industrial and Engineering Chemistry Research, vol. 50, no. 18, pp. 10393-10399, 2011.

[17] Z. Amjad, "Investigations on the evaluation of polymeric calcium sulfate dihydrate (gypsum) scale inhibitors in the presence of phosphonates," Desalination and Water Treatment, vol. 37, no. 1-3, pp. 268-276, 2012.

[18] L. Ling, Y. Zhou, J. Huang et al., "Carboxylate-terminated double-hydrophilic block copolymer as an effective and environmental inhibitor in cooling water systems," Desalination, vol. 304, pp. 33-40, 2012.

[19] T. A. Hoang, H. M. Ang, and A. L. Rohl, "Investigation into the effects of phosphonic inhibitors on the formation of calcium sulfate scales," Desalination and Water Treatment, vol. 29, no. 1-3, pp. 294-301, 2011. 
[20] Z. Amjad and P. G. Koutsoukos, "Evaluation of maleic acid based polymers as scale inhibitors and dispersants for industrial water applications," Desalination, vol. 335, no. 1, pp. 55-63, 2014.

[21] H. Wang, Y. Zhou, Q. Yao, and W. Sun, "Calcium sulfate precipitation studies with fluorescent-tagged scale inhibitor for cooling water systems," Polymer Bulletin, vol. 72, no. 9, pp. 21712188, 2015.

[22] Y. Zhao, L. Jia, K. Liu, P. Gao, H. Ge, and L. Fu, "Inhibition of calcium sulfate scale by poly (citric acid)," Desalination, vol. 392, pp. 1-7, 2016.

[23] NACE, "Laboratory screening tests to determine the ability of scale inhibitors to prevent the precipitation of calcium sulfate and calcium carbonate from solution (for oil and gas production systems)," NACE Standard TM0374-2007 (formerly TM03742001). Item No. 21208, 2007.

[24] "Ionic Strength Corrections for Stability Constants using Specific Interaction Theory (SIT) for Windows 9x, NT, 2000, and xp, Pettit, L. D. Academic Software, IUPAC," 2003, available on the IUPAC site, https://iupac.org/, http://www.acadsoft.co.uk/.

[25] K. I. Popov, V. E. Larchenko, and L. V. Krinitskaya, "Study of the composition of industrially manufactured phosphonates. Saltdeposition inhibitor low-activity 1-hydroxyethylidenediphosphonic acid (HEDP MA)," Khimicheskaya Promyshlennost, no. 10, pp. 663-665, 1996 (Russian).

[26] K. I. Popov, H. Rönkkömäki, and L. H. J. Lajunen, "Critical evaluation of stability constants of phosphonic acids," Pure and Applied Chemistry, vol. 73, no. 10, pp. 1641-1677, 2001.

[27] K. Popov, G. Rudakova, V. Larchenko et al., "A comparative performance ranking of some phosphonates and environmentally friendly polymers on $\mathrm{CaCO}_{3}$ scaling inhibition by NACE protocol," Desalination and Water Treatment, In press.

[28] A. Antony, J. H. Low, S. Gray, A. E. Childress, P. Le-Clech, and G. Leslie, "Scale formation and control in high pressure membrane water treatment systems: a review," Journal of Membrane Science, vol. 383, no. 1-2, pp. 1-16, 2011.

[29] L. X. Liu and A. J. He, "Research progress of scale inhibition mechanism," in Pollution Control Project, Removal and Treatment Technologies, vol. 955-959 of Advanced Materials Research, chapter 10, pp. 2411-2414, 2014.

[30] M. B. Tomson, G. Fu, M. A. Watson, and A. T. Kan, "Mechanisms of mineral scale inhibition," SPE Production \& Facilities, vol. 18, no. 3, pp. 192-199, 2003.

[31] Y. M. Al-Roomi and K. F. Hussain, "Potential kinetic model for scaling and scale inhibition mechanism," Desalination, vol. 393, pp. 186-195, 2016.

[32] R. Greenwood, "Review of the measurement of zeta potentials in concentrated aqueous suspensions using electroacoustics," Advances in Colloid and Interface Science, vol. 106, no. 1-3, pp. 55-81, 2003.

[33] H. Shemer, D. Hasson, and R. Semiat, "Review of the state of the art of antiscalant selection," in Proceedings of the 244th ACS National Meeting \& Exposition, COLL-165, Philadelphia, $\mathrm{Pa}$, USA, August 2012.

[34] K. I. Popov, N. E. Kovaleva, G. Y. Rudakova, S. P. Kombarova, and V. E. Larchenko, "Recent state-of-the-art of biodegradable scale inhibitors for cooling-water treatment applications (review)," Thermal Engineering, vol. 63, no. 2, pp. 122-129, 2016. 

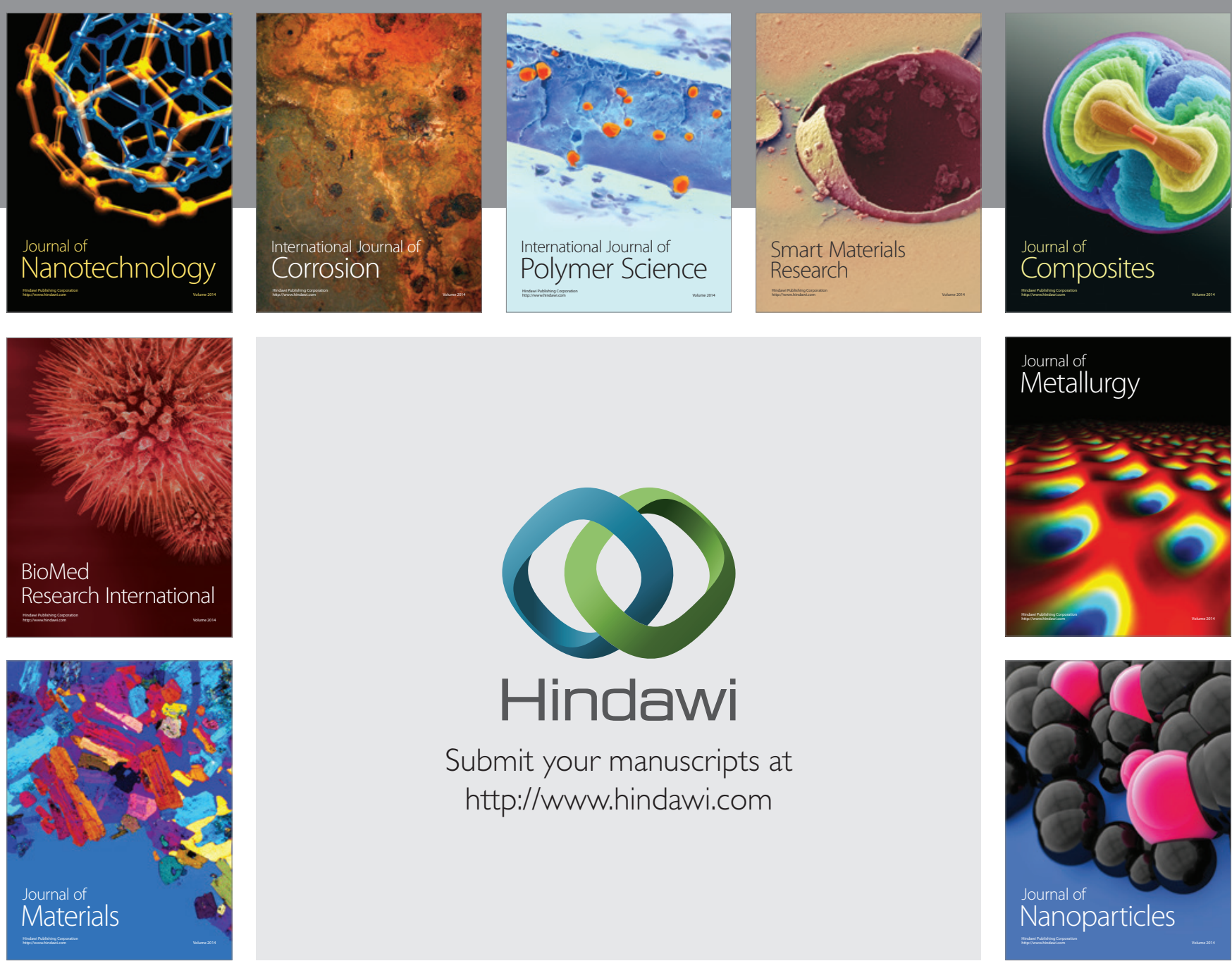

\section{Hindawi}

Submit your manuscripts at

http://www.hindawi.com

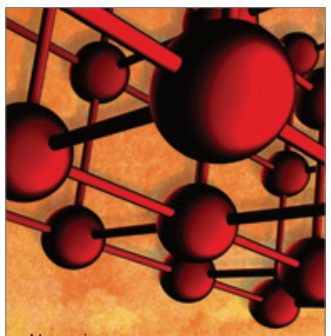

Materials Science and Engineering
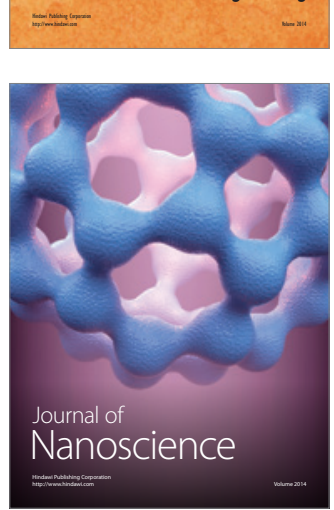
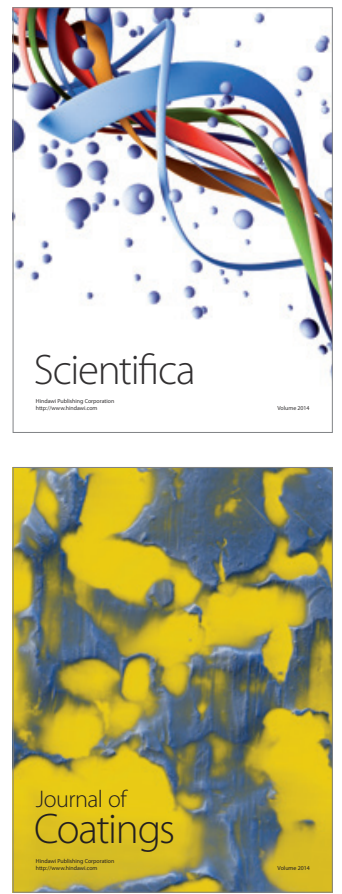
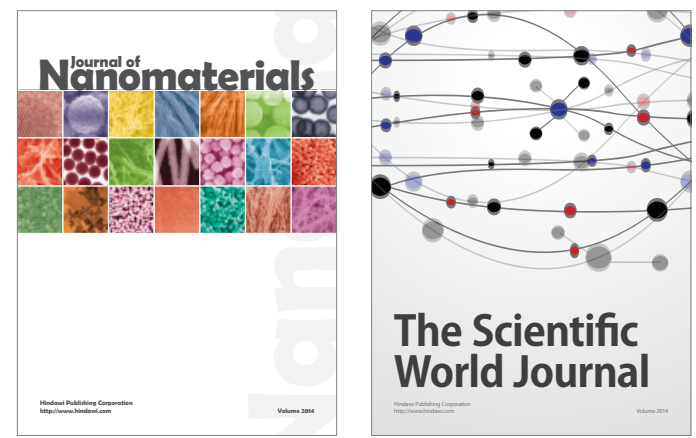

The Scientific World Journal
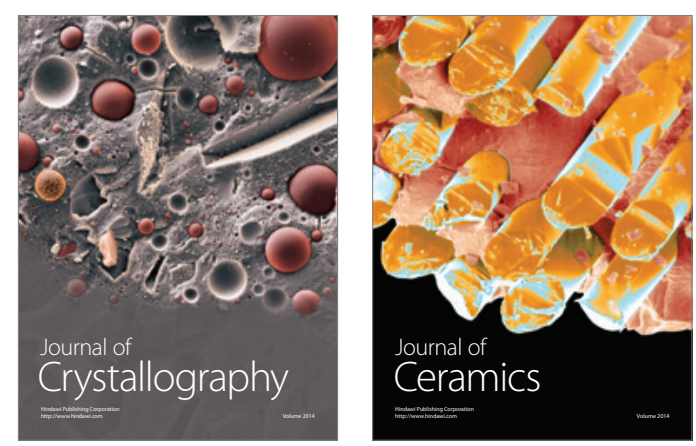
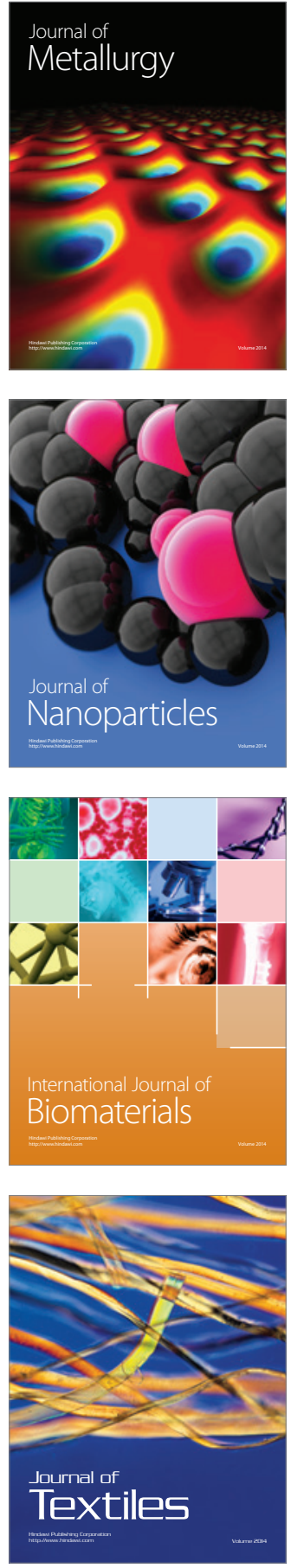